American Journal of Applied Sciences 7 (7): 933-936, 2010

ISSN 1546-9239

(C) 2010 Science Publications

\title{
Effects of Extractants on the Yields and Selected Chemical Characteristics of Humic Acids Isolated from Tropical Saprists Peat
}

\author{
Lee Jia Huey, Osumanu Haruna Ahmed and Nik Muhamad Ab. Majid \\ Department of Crop Science, Faculty of Agriculture and Food Science, \\ University Putra Malaysia Bintulu Campus, Sarawak, 97008 Bintulu, Sarawak, Malaysia
}

\begin{abstract}
Problem statement: Humic acids are beneficial to soil aggregation, binding of heavy metal, plant growth and many more. However, the isolation of Humic Acids (HA) from its origin is not only time-consuming, but the isolation is also affected by factors such as temperature and the types of extractants and their concentrations. Different concentrations of extractant are said to alter the chemical characteristics of HA. Although this kind of information is important in HA studies, it is lacking for tropical peats. Approach: This study was conducted to investigate the yields and selected chemical element contents of HA isolated from tropical saprists peat as affected by $\mathrm{NaOH}$ and $\mathrm{KOH}$ with different concentrations. Humic acids were isolated from tropical saprists peat taken from Sarawak, Malaysia. Yields of HA and selected chemical properties were determined using standard procedures. Results: Yields of HA isolated using different concentrations of $\mathrm{NaOH}$ and $\mathrm{KOH}$ showed significant difference at each level of concentrations. For the chemical characteristics tested, only total acidity showed no significant difference. For TOC and ash, the $\mathrm{KOH}$ used exhibited inconsistent results compared to that of $\mathrm{NaOH}$. As for $\mathrm{E}_{4} / \mathrm{E}_{6}$ values, the high values obtained suggests that $\mathrm{HA}$ in Sarawak peats contain relatively lower molecular weight. Conclusion: For the purpose of studying chemical characteristics, $0.2,0.3$ and $0.4 \mathrm{M}$ of both $\mathrm{NaOH}$ and $\mathrm{KOH}$ were good enough to be used in isolating HA. This is because the results of study showed that these 3 levels of concentrations yielded HA with more homogenous chemical characteristics. On the other hand, extractants with higher concentrations are preferred when the yield of HA is of concern.
\end{abstract}

Key words: Humic substances, extractants, humic acids, tropical peats

\section{INTRODUCTION}

Generally, humic matter, or humic material, refers to the humified organic material fraction of humus. Based on solubility, humic matter can be further divided into three groups, namely Fulvic Acids (FA), Humic Acids (HA) and humin (Brady and Weil, 2002). A collective term for these groups is humic substances. Humic substances are mixture of amorphous, polydispersed substances with yellow, brown to black colour. Other common characteristics including hydrophilic, acidic and high in molecular weight (Hayes, 2006), ranging from several hundreds to thousands of atomic units or Daltons are well known. Humic substances can be found in all terrestrial and aquatic environments. Isolation of humic substances can be accomplished according to a fractionation scheme based on their water solubility under acidic or alkaline conditions (Zaccone et al., 2007).

In agriculture, humic matter has drawn the attention of many scientists as the performance of crops have always been better when they are grown in soils rich in humic matter. Studies have shown that HA is in general beneficial to plant, such as growth promoting, tolerance to soil contaminant or utilization of nitrogenous fertilizer (Atiyeh et al., 2002; Tan and Binger, 1986; Tan and Nopamornbodi, 1979). However, isolation of humic substances such as HA is laborious and time consuming. Factors that affect the quality and quantity of HA yield isolated from soils include extraction, fractionation and purification periods, types of extractants (Zaccone et al., 2007) and others. Common extractants include neutral pyrophosphate, mixture of pyrophosphate, sodium hydroxide and potassium hydroxide (Hayes, 2006). However, some reagents are said to induce autooxidation of humic substances. This alters the chemical composition of HA. Besides the nature of reagents, concentration of the reagents play important role too. For instance, stronger $\mathrm{NaOH}$ solution extracts more HA but it alters the chemical characteristics of HA.

Corresponding Author: Lee Jia Huey, Department of Crop Science, Faculty of Agriculture and Food Science, University Putra Malaysia Bintulu Campus, Sarawak, 97008 Bintulu, Sarawak, Malaysia 
Previous investigations on the influence of various extractants on the yields or structural properties of HA have been focused mainly on mineral soil HA. In contrast, relatively little attention has been devoted to HA isolated from peat (Zaccone et al., 2009), especially tropical peat. Thus, the objective of this study was to investigate the yields and selected chemical element contents of HA isolated from tropical saprists peat as affected by 2 different extractants $(\mathrm{NaOH}$ and $\mathrm{KOH})$ with different concentrations.

\section{MATERIALS AND METHODS}

Peat soil (saprists) samples were taken at $0-15 \mathrm{~cm}$ of secondary forest adjacent to an oil palm plantation at Kuala Tatau, Sarawak, Malaysia using peat auger. Humic acids isolation was carried out by the method of Stevenson (1994) and Ahmed et al. (2005) with some modifications. Ten gram (dry-weight basis) peat soil samples were placed into polyethylene centrifuge bottles and $100 \mathrm{~mL}$ extractant at different concentrations was added. The bottles were stoppered tightly with rubber stoppers, followed by equilibrating at room temperature on a reciprocal mechanical shaker $(24 \mathrm{~h}, 180 \mathrm{rpm})$. At the end of the shaking period, samples were centrifuged at $21,000 \mathrm{G}$ for $15 \mathrm{~min}$ (Susilawati et al., 2008). The dark colored supernatant liquors were decanted while the $\mathrm{pH}$ of the solutions was adjusted to one (Zaccone et al., 2007). Afterwards, the solutions were allowed to equilibrate at room temperature.

Fractionation starts right after acidification. The period used in this study was $24 \mathrm{~h}$. At the end of fractionation period, the solutions were transferred into polyethylene bottles and centrifuged at 21,000G for $10 \mathrm{~min}$. The supernatant part of the samples (FA) was decanted. The remainder parts which contained HA were purified following a modification of the method of Ahmed et al. (2005) by washing them in $100 \mathrm{~mL}$ of distilled water through centrifugation at $21,000 \mathrm{G}$ for $10 \mathrm{~min}$ with the purpose of reducing mineral matter and $\mathrm{HCl}$. This procedure was repeated five times. The washed HA samples were oven-dried at $40^{\circ} \mathrm{C}$ to a constant weight, weighed and yields expressed as percentage by weight of HA in the soil samples used. The whole isolation procedure was replicated four times.

The elemental composition of HA obtained was analyzed to determine the influence of extractant on HA. Prior to analysis, the HA samples were ground into fine powder to ensure homogeneity. Total Organic Carbon (TOC) was determined by dry combustion method (Cheftetz et al., 1996). Ash content was determined by combusting $\mathrm{HA}$ at $750^{\circ} \mathrm{C}$ (Inbar et al., 1990). Analysis of functional groups (carboxylic, phenolic and total acidity) of HA was conducted according to the method described by (Inbar et al., 1990). Humification level of HA was ascertained by $\mathrm{E}_{4} / \mathrm{E}_{6}$ ratio followed the method described by Stevenson (1994).

Analysis Of Variance (ANOVA) was performed to detect treatments effect using Statistical Analysis Software (SAS) version 9.1. Tukey's test at $\mathrm{p}=0.05$ was conducted for separation of means.

\section{RESULTS}

Data obtained (Fig. 1) shows that different concentrations of extractant affected the yields of HA significantly, regardless of the type of extractant. Comparison between the 2 extractants showed that only the yields of HA using 0.1 and $0.3 \mathrm{M}$ were significantly different yields of HA. In the case of the other 4 concentrations tested, yields of HA isolated by using $\mathrm{NaOH}$ and $\mathrm{KOH}$ did not differ significantly.

As shown Table 1, TOC did not show significant difference across different levels of $\mathrm{NaOH}$ concentrations except for $0.6 \mathrm{M}$. As for $\mathrm{KOH}$, the condition was getting more complicated starting from $0.3 \mathrm{M}$. Similar to $\mathrm{NaOH}, 0.6 \mathrm{M}$ of $\mathrm{KOH}$ also exhibited significantly different values of TOC compared to other concentrations except for $0.5 \mathrm{M}$. Comparison between the 2 extractants with same concentrations showed no significant difference except for $0.5 \mathrm{M}$. The data on ash (Table 2) showed similar pattern as that of TOC.

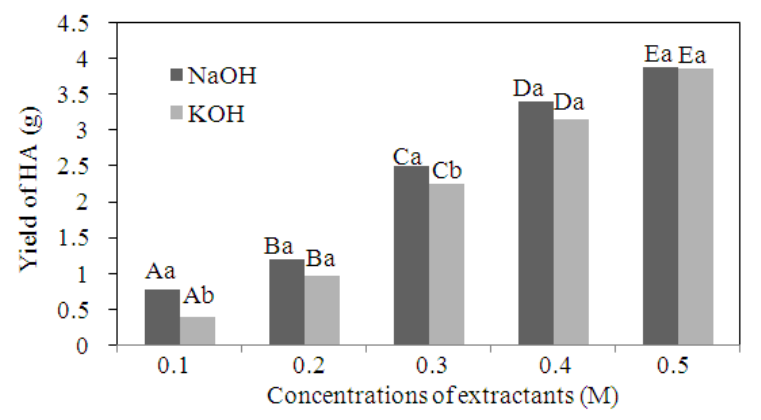

Fig. 1: Yield (g) of HA isolated using different concentrations of $\mathrm{NaOH}$ and $\mathrm{KOH}$; Means with the same capital letter within the same row are not significantly different at $\mathrm{p}=0.05$ (Tukey's test). Means with the same letter within the same column are not significantly different at $\mathrm{p}=0.05$ (Tukey's test) 
Am. J. Applied Sci., 7 (7): 933-936, 2010

Table 1: Total organic carbon (\%) of HA isolated as affected by different concentrations of $\mathrm{NaOH}$ and $\mathrm{KOH}$

\begin{tabular}{llllll}
\hline Extractants & $0.1 \mathrm{M}$ & $0.2 \mathrm{M}$ & $0.3 \mathrm{M}$ & $0.4 \mathrm{M}$ & $0.5 \mathrm{M}$ \\
\hline
\end{tabular}

$\mathrm{NaOH} \quad 57.227$ Aa 57.517 Aa $56.550 \mathrm{Aa} \quad 55.873 \mathrm{Aa} \quad 55.497 \mathrm{Aa}$

$\mathrm{KOH} \quad 57.517$ Aa 57.420 Aa $56.357 \mathrm{ABa} 54.907 \mathrm{ABa} 53.650 \mathrm{Bb}$

Note: Means with the same capital letter within the same row are not significantly different at $\mathrm{p}=0.05$ (Tukey's test). Means with the same letter within the same column are not significantly different at $\mathrm{p}=0.05$ (Tukey's test)

Table 2: Ash (\%) of HA isolated by different concentrations of $\mathrm{NaOH}$ and $\mathrm{KOH}$

\begin{tabular}{llllll}
\hline Extractants & $0.1 \mathrm{M}$ & $0.2 \mathrm{M}$ & $0.3 \mathrm{M}$ & $0.4 \mathrm{M}$ & $0.5 \mathrm{M}$ \\
\hline $\mathrm{NaOH}$ & $1.334 \mathrm{Aa}$ & $0.834 \mathrm{Aa}$ & $2.500 \mathrm{Aa}$ & $3.667 \mathrm{Aa}$ & $4.334 \mathrm{Aa}$
\end{tabular}

$\begin{array}{llllll}\mathrm{KOH} & 0.834 \mathrm{Aa} & 1.000 \mathrm{Aa} & 2.833 \mathrm{ABa} & 5.333 \mathrm{ABa} & 7.500 \mathrm{Bb}\end{array}$

Note: Means with the same capital letter within the same row are not significantly different at $\mathrm{p}=0.05$ (Tukey's test). Means with the same letter within the same column are not significantly different at $\mathrm{p}=0.05$ (Tukey's test)

Table 3: Total acidity $\left(\mathrm{cmol} / \mathrm{kg}^{-1}\right)$ of HA isolated by different concentrations of $\mathrm{NaOH}$ and $\mathrm{KOH}$

\begin{tabular}{llllll}
\hline Extractants & $0.1 \mathrm{M}$ & $0.2 \mathrm{M}$ & $0.3 \mathrm{M}$ & $0.4 \mathrm{M}$ & $0.5 \mathrm{M}$ \\
\hline
\end{tabular}

\begin{tabular}{llllll}
\hline $\mathrm{NaOH}$ & $868.75 \mathrm{Aa}$ & $925.00 \mathrm{Aa}$ & $875.00 \mathrm{Aa}$ & $912.50 \mathrm{Aa}$ & $856.25 \mathrm{Aa}$
\end{tabular}

$\mathrm{KOH} \quad 862.50 \mathrm{Aa} \quad 856.25 \mathrm{Aa} \quad 875.00 \mathrm{Aa} \quad 831.25 \mathrm{Aa} \quad 856.25 \mathrm{Aa}$

Note: Means with the same capital letter within the same row are not significantly different at $\mathrm{p}=0.05$ (Tukey's test). Means with the same letter within the same column are not significantly different at $\mathrm{p}=0.05$ (Tukey's test)

Table 4: $\mathrm{E}_{4} / \mathrm{E}_{6}$ value of $\mathrm{HA}$ isolated by different concentrations of $\mathrm{NaOH}$ and $\mathrm{KOH}$

\begin{tabular}{llllll}
\hline Extractants & $0.1 \mathrm{M}$ & $0.2 \mathrm{M}$ & $0.3 \mathrm{M}$ & $0.4 \mathrm{M}$ & $0.5 \mathrm{M}$ \\
\hline $\mathrm{NaOH}$ & $7.0490 \mathrm{Ba}$ & $8.6837 \mathrm{Aa}$ & $8.5339 \mathrm{Aa}$ & $8.2683 \mathrm{Aa}$ & $7.8202 \mathrm{ABa}$
\end{tabular}

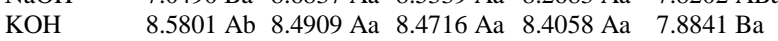

Note: Means with the same capital letter within the same row are not significantly different at $\mathrm{p}=0.05$ (Tukey's test). Means with the same letter within the same column are not significantly different at $\mathrm{p}=0.05$ (Tukey's test)

In both comparison between 2 extractants and comparison among different concentrations of 1 extractant, the value of total acidity did not exhibit any significant difference (Table 3).

Comparison of $\mathrm{E}_{4} / \mathrm{E}_{6}$ values among different concentrations of $\mathrm{NaOH}$ showed that $0.1 \mathrm{M}$ was significantly different from others (Table 4). This observation was different from what was observed in $\mathrm{KOH}$. Apart from 0.5 and $0.6 \mathrm{M} \mathrm{KOH}$, the $\mathrm{E}_{4} / \mathrm{E}_{6}$ values as affected by other concentrations were not significantly different. As for comparison between extractants, only $0.1 \mathrm{M}$ showed significant different result.

\section{DISCUSSION}

It is generally agreed that the higher the concentration of extractant, the higher the yield of HA (Stevenson, 1994). Hence, it can be concluded from Table 1 that isolation of HA from tropical saprists peat by using both $\mathrm{NaOH}$ and $\mathrm{KOH}$, agreed with the above mentioned statement. This observation could be associated with the exchange ability of extractant. With more $\mathrm{Na}^{+}$and $\mathrm{K}^{+}$, the exchange process happened at the hydroxyl and carboxylic functional groups of peat was more complete for the extractant with higher concentration compared to isolation by using low concentration of extractants. Apart from this, Stevenson (1994) also pointed out that the organic matter extracted from soil with increasing concentration of alkali might be due to slow depolymerization of high molecular weight complexes. In the comparison between 2 extractants, only 0.1 and $0.3 \mathrm{M}$ showed significant difference. This might due to stronger reactivity of $\mathrm{Na}^{+}$ compared to $\mathrm{K}^{+}$in binding soil organic matter. However, when the concentration increased, the effect of the reactivity was not so obvious.

Values of TOC from HA isolated in this study were within the range reported by $\mathrm{Li}$ et al. (2003) and Stevenson (1994). Humic acids isolated by different concentrations of $\mathrm{NaOH}$ did not show significant difference in TOC. The trend for $\mathrm{KOH}$ was inconsistent as there was no single $\mathrm{KOH}$ concentration that was significantly different from other concentrations. However, $0.5 \mathrm{M} \mathrm{KOH}$ did show significant difference in TOC value compared to those of 0.1 and $0.2 \mathrm{M}$. For comparison between the 2 extractants, significant difference was only detected in the concentration level of 0.5 M. According to Krosshavn et al. (1992), there was significant loss of carbon in the extraction of humic substances by using $0.5 \mathrm{M} \mathrm{NaOH}$ as extracting solution. Though the TOC value of HA isolated by $\mathrm{NaOH}$ was higher than the one isolated by $\mathrm{KOH}$, the above mentioned statement suggests the possible cause of this difference.

The value of ash was in general agreement with what was reported by (Zaccone et al., 2007). The overall trend was similar to that of TOC (no significant difference among the 5 concentrations of $\mathrm{NaOH}$ as compared to those of $\mathrm{KOH}$ ). Though there was no significant difference compared to others, the TOC values of 0.1 and $0.2 \mathrm{M}$ (using both $\mathrm{NaOH}$ and $\mathrm{KOH}$ ) were considered very low. This suggests that lower concentrations of extractant tend to isolate HA with less alteration on chemical characteristics. However, in the comparison between 2 extractants, only $0.5 \mathrm{M}$ showed significant difference. Generally $\mathrm{K}^{+}$is weaker than $\mathrm{Na}^{+}$ in exchange ability. The isolation of HA using $0.5 \mathrm{M}$ $\mathrm{KOH}$ might not be as effective as using $0.5 \mathrm{M} \mathrm{NaOH}$. Hence, HA isolated by $0.5 \mathrm{M} \mathrm{KOH}$ might contain more foreign materials than the one isolated by $0.5 \mathrm{M} \mathrm{NaOH}$.

Total acidity obtained in this study was consistent with those reported by Campitelli et al. (2006) and also Stevenson (1994). The value of total acidity, either 
compared within the same column or compared within the same row, showed no significant difference. Hence, it could be concluded that both extractants and concentration had no effect on the values of carboxylic and phenolic groups of HA.

The $E_{4} / E_{6}$ values reported in this study were slightly higher compared to the one reported by Sim and Mohamed (2007). According to Stevenson (1994), $\mathrm{E}_{4} / \mathrm{E}_{6}$ value has an inverse relationship with molecular weight of humic substances. The relatively high value reported in this study indicated that HA isolated is lower in molecular weight. The above mentioned statement is supported by the study of Sim and Mohamed (2007) as their study showed that Sarawak humic substances possess relatively lower molecular weight. Comparison between the 2 extractants showed no significant difference in all the concentrations tested, except for $0.1 \mathrm{M}$. Both $\mathrm{Na}$ and $\mathrm{K}$ are in the same group of periodic table. This might be the possible reason why their chemical reaction is similar to each other.

\section{CONCLUSION}

Humic substances have been extracted from different origins for different purposes. For the purpose of maintain HA chemical characteristics, $0.2,0.3$ and $0.4 \mathrm{M}$ of both $\mathrm{NaOH}$ and $\mathrm{KOH}$ could be a good choice as the results of study showed that these concentrations yielded HA with less difference in the chemical characteristics of the isolated HA. However, if yield of HA is of concern, extractants with higher concentration should be used.

\section{ACKNOWLEDGEMENT}

The researchers acknowledge the financial support of University Putra Malaysia, Malaysia for this study.

\section{REFERENCES}

Ahmed, O.H., M.H. Husni, A.R. Anuar and M.M. Hanafi, 2005. Effects of extraction and fractionation time on the yield of compost humic acids. New Zealand J. Crop Hortic. Sci., 33: 107-110. DOI: 10.1080/01140671.2005.9514338

Atiyeh, R.M., S. Lee, C.A. Edwards, N.Q. Arancon and J.D. Metzger, 2002. The influence of humic acids derived from earthworm-processed organic wastes on plant growth. Bioresour. Technol., 84: 7-14. DOI: 10.1016/S0960-8524(02)00017-2

Brady, N.C. and R.R. Weil, 2002. The Nature and Properties of Soils. 13th Edn., Prentice Hall, ISBN: 9780130167637, pp: 959.
Campitelli, P.A., M.I. Velasco and S.B. Ceppi, 2006. Chemical and physiochemical characteristics of humic acids extracted from compost, soil and amended soil. Talanta, 69: 1234-1239. DOI: 10.1016/j.talanta.2005.12.048

Cheftetz, B., P.H. Hatcher, Y. Hadar and Y. Chen, 1996. Chemical and biological characterization of organic matter during composting of municipal solid waste. J. Environ. Q., 25: 776-785.

Hayes, M.H.B., 2006. Solvent system for the isolation of organic components from soils. Soil Sci. Soc. Am. J., 70: 986-994. DOI: 10.2136/sssaj2005.0107

Inbar, Y., Y. Chen and Y. Hadar, 1990. Humic substances formed during the composting of organic matter. Soil Sci. Soc. Am. J., 54: 1316-1323.

Krosshavn, M., I. Kogel-Knaber, T.E. Southon and E. Steinnes, 1992. The influence of humus fractionation on the chemical composition of soil organic matter studied by solid-state 13C NMR. Eur. J. Soil Sci., 43: 473-483. DOI: 10.1111/j.1365-2389.1992.tb00153.x

Li, L., W.L. Huang, P.A. Peng, G.Y. Sheng and J.M. Fu, 2003. Chemical and molecular heterogeneity of humic acids repetitively extracted from a peat. Soil Sci. Soc. Am. J., 67: 740-746.

Sim, S.F. and M. Mohamed, 2007. Chemicla characterization of humic substances occuring in the peats of Sarawak, Malaysia. Organic Geochem., 38: 967-976. DOI: 10.1016/j.orggeochem.2006.12.010

Stevenson, F.H., 1994. Humus Chemistry: Genesis, Composition, Reactions. 2nd Edn., John Wiley and Sons Inc., ISBN: 9780471594741, pp: 496.

Susilawati, K., H.A. Osumanu, A.M. Nik Muhamad and Y. Mohd Khanif, 2008. Simple method of purifying humic acids isolated from tropical hemists (peat soil). Am. J. Applied Sci., 5: 1812-1815.

Tan, K.H. and A. Binger, 1986. Effect of humic acid on aluminum toxicity in corn plants. Soil Sci., 141: 20-25.

Tan, K.H. and N. Nopamornbodi, 1979. Effect of different levels of humic acids on nutrient content and growth of corn (Zea mays L.) Plant and Soil, 51: 283-287. DOI: 10.1007/BF02232891

Zaccone, C., C. Cocozza, V. D’Orazio, C. Plaza, A. Cheburkin and T.M. Miano, 2007. Influence of extractant on quality and trace elements content of peat humic acids. Talanta, 73: 820-830. DOI: 10.1016/j.talanta.2007.04.052

Zaccone, C., P. Soler-Rovira, C. Plaza, C. Cocozza and T.M. Miano, 2009. Variability in As, Ca, Cr, K, $\mathrm{Mn}, \mathrm{Sr}$ and $\mathrm{Ti}$ concentrations among humic acids isolated from peat using $\mathrm{NaOH}, \mathrm{Na}_{4} \mathrm{P}_{2} \mathrm{O}_{7}$ and $\mathrm{NaOH}+\mathrm{Na}_{4} \mathrm{P}_{2} \mathrm{O}_{7}$ solutions. J. Hazard. Mater., 167: 987-999. DOI: 10.1016/j.jhazmat.2009.01.078 